\title{
Association study of COX-2 (PTGS2) -765 G/C promoter polymorphism by pyrosequencing in Sicilian patients with Alzheimer's disease
}

\author{
Salemi Michele ${ }^{1}$, Maria Grazia Salluzzo ${ }^{1}$, Aldo E. Calogero², Ferri Raffaele ${ }^{1}$, Paolo Bosco ${ }^{1}$
}

${ }^{1}$ IRCCS Associazione Oasi Institute for Research on Mental Retardation
and Brain Aging, Troina, Italy
2Section of Endocrinology, Andrology and Internal Medicine, Department
of Medical and Pediatric Sciences, University of Catania, Catania, Italy

Submitted: 18 February 2013

Accepted: 18 June 2013

Arch Med Sci 2014; 10, 6: 1235-1238

DOI: $10.5114 /$ aoms.2014.47832

Copyright @ 2014 Termedia \& Banach

\section{Abstract}

Introduction: Alzheimer's disease (AD) is characterized by progression of memory problems to a slow global decline of cognitive function. Inflammation when left unregulated becomes a major cofactor in the pathogenesis of AD. PTGS2 is of crucial relevance in the inflammatory response, and it has been shown to play a considerable role in AD pathogenesis.

Material and methods: To assess the possible putative role of a PTGS2 polymorphism $(-765 \mathrm{G} / \mathrm{C})$ in $\mathrm{AD}$ patients, we examined, by pyrosequencing, its distribution in 84 Sicilian AD patients and in 80 controls.

Results: No significant statistical difference in PTGS2 $-765 \mathrm{G} / \mathrm{C}$ genotype distribution was found comparing patients with $A D$ and controls. In addition, no significant difference was observed in the distribution of the PTGS2 -765 alleles between AD patients and controls.

Conclusions: These findings suggest that the PTGS2 $-765 \mathrm{G} / \mathrm{C}$ polymorphism may not be associated with $A D$ in the Sicilian population.

Key words: Alzheimer disease, COX-2 gene, polymorphism, pyrosequencing.

\section{Introduction}

Dementia has been estimated to affect about 25 million persons worldwide and it is projected to nearly double every 20 years, reaching about 66 million in 2030 and about 115 million in 2050. The total number of new cases of dementia each year is nearly 7.7 million worldwide, implying one new case every $4 \mathrm{~s}$ [1]. About $60-70 \%$ of cases of dementia are due to Alzheimer's disease (AD).

The AD is clinically characterized by progression from episodic memory problems to a slow global decline of the cognitive function that leaves patients with end-stage AD bedridden and dependent on custodial care, with death occurring on average 9 years after diagnosis [2]. Neuropathologically, $A D$ is characterized by the presence of extracellular amyloid deposits composed of aggregated $\beta$-amyloid $(A \beta)$ peptides and intracellular neurofibrillary tangles containing hyperphosphorylated, aggregated tau protein [2]. To date, the etiological mechanisms underlying the neuropathological changes in AD remain unknown; on the other hand, inflammation is a fundamental protective immunological response, but when

\author{
Corresponding author: \\ Dr. Salemi Michele \\ IRCCS Associazione Oasi \\ Institute \\ for Research on Mental \\ Retardation \\ and Brain Aging \\ Troina, Italy \\ Phone: +39935936440 \\ Fax: +39935936593 \\ E-mail: msalemi@oasi.en.it, \\ micezia@tiscali.it
}


left unregulated, it can become a major cofactor in the pathogenesis of many chronic human diseases, including $A D$. The role of neuroinflammation in $A D$ has been intensely investigated, in part because of its tremendous clinical implications [2].

Prostaglandin-endoperoxide synthase 2 (PTGS2), also called cyclooxygenase 2 (COX2) (MIM\# 600262), has been shown to be expressed mostly in the central nervous system and inflammatory cells $[3,4]$. The gene coding for PTGS2 has been mapped to $1 \mathrm{q} 31.1$ between two regions to which genetic linkage to $A D$ has been reported [5]. In addition, elevated PTGS2 levels are present in neurons from hippocampal pyramidal regions of the AD brain [6]. A number of single nucleotide polymorphisms (SNPs) have been described in the promoter region of the PTGS2 gene that probably regulates its transcription, but only one polymorphism located at position $-765 \mathrm{G} / \mathrm{C}$, a putative stimulatory protein-1 binding site, has been shown to be functional [7]. The C allele of COX2765 polymorphism has been associated with decreased risk of $A D$ [7]; however, other findings seem to suggest that the distribution of COX2$765 \mathrm{G} / \mathrm{C}$ polymorphism is similar between patients with $\mathrm{AD}$ and controls [8].

Pyrosequencing is a DNA sequencing technology based on the sequencing-by-synthesis principle [9], and the method is based on a real-time bioluminescence technique. Gharizadeh et al. analyzed in detail the sequence data of a large number of amplicons, using two techniques (pyrosequencing and Sanger dideoxy sequencing). Their results demonstrate that for short DNA sequences, pyrosequencing excels in reducing sample preparation time, providing ease-of-use and cost and labor savings [10]. Also, the drawbacks of pyrosequencing are rapidly being addressed with the use of Sequenase, and automated software [10]. In the present study, we evaluated the -765 G/C promoter variant of the PTGS2 gene by pyrosequencing technology in Sicilian patients with $A D$ and in normal controls.

\section{Material and methods}

\section{Patients}

A total of 164 subjects, including 84 AD patients (41 males and 43 females; mean age: 75.9 \pm 7.8 years; age range: $56-95$ years) and 80 normal subjects ( 37 males and 43 females; mean age: $77.3 \pm 8.5$ years; age range: $56-95$ ) were recruited at the IRCCS Associazione Oasi of Troina (Italy). The diagnosis of probable AD was made according to the recent National Institute of Aging (NIA) and Alzheimer's Association (AA) work group (NIA-AA) revision of the diagnostic criteria that enlarges the window for the detection of the disease to the early stages [11]. Symptoms of cognitive impairment or family history of dementia were exclusion criteria for the controls. Written informed consent was obtained from the participants or from their families. Patients and controls were all born in Sicily and were of European origin.

\section{DNA extraction, polymerase chain reaction amplification and pyrosequencing}

DNA was isolated from a lymphocyte-enriched fraction of whole blood. The procedures for detecting the single nucleotide polymorphism (SNP rs 20417) of the $-765 \mathrm{G} / \mathrm{C}$ promoter variant in the PTGS2 gene were based on polymerase chain reaction (PCR) amplification and pyrosequencing technology (PyroMark ID instrument; Biotage, Uppsala, Sweden) as previously described [12]. Biotinylated PCR primer sequences for the amplification of PTGS2 promoter variant sites were selected according to the same previously published study [12]. Five $\mu$ l of DNA were added to produce $50 \mu \mathrm{l}$ of PCR solution mixture that contained $0.2 \mathrm{mmol}$ of each dNTP, $1.5 \mathrm{mmol} / / \mathrm{MgCl}_{2}, 1 X \mathrm{PCR}$ buffer, 20 pmol of each primer and $1.5^{2}$ units of DNA Taq polymerase. The PCR was performed with an initial denaturation for $5 \mathrm{~min}$ at $95^{\circ} \mathrm{C}$ followed by 40 cycles of $30 \mathrm{~s}$ at $95^{\circ} \mathrm{C}, 30 \mathrm{~s}$ at $56^{\circ} \mathrm{C}, 30 \mathrm{~s}$ at $72^{\circ} \mathrm{C}$ and a final incubation for $10 \mathrm{~min}$ at $72^{\circ} \mathrm{C}$. PCR products were resolved by agarose gel electrophoresis to confirm successful amplification. The biotinylated products were then immobilized to streptavidin-coated beads using a solution from a commercial PSQ TM 96 sample preparation kit (Biotage, Uppsala, Sweden). Beads $(3 \mu \mathrm{l})$ were diluted in $15 \mu \mathrm{l}$ of binding buffer with $10 \mu \mathrm{l}$ of biotinylated PCR products, incubated for $10 \mathrm{~min}$ at room temperature and then transferred to a filter probe where the liquid was removed by vacuum filtration. DNA in the denaturation solution was separated, the templates were washed with washing buffer, transferred to a PSQ 96 SNP plate (Biotage, Uppsala, Sweden) and annealed with the sequencing primers described by Skarke et al. [12], in annealing buffer at room temperature. Finally, the samples were analyzed using a PyroMark ID System and the SNP reagent kit (both purchased from Biotage, Uppsala, Sweden).

\section{Statistical analysis}

Fisher's exact test was used for comparisons in $2 \times 2$ and $2 \times 3$ contingency tables. Statistical significance was accepted when the $p$ value was lower than 0.05 . The power of the study was calculated by the methods of Cohen [13]. The $\chi^{2}$ test was use to determine whether there was a significant difference between the number of actual and expected genotypes in Hardy-Weinberg equilibrium. 
Table I. Genotype frequencies of PTGS2 -765 G/C polymorphism in patients with Alzheimer's disease (AD) and controls

\begin{tabular}{|lccc|}
\hline Genotype & Controls (\%) & AD patients (\%) & Value of $p$ \\
\hline GG & $49(61.2)$ & $55(65.5)$ & 0.381 \\
\hline GC & $24(30.0)$ & $26(30.9)$ & \\
\hline CC & $7(8.8)$ & $3(3.6)$ & \\
\hline Total & $80(100)$ & $84(100)$ & \\
\hline
\end{tabular}

Table II. Allele frequencies of PTGS2 -765 G/C polymorphism in patients with Alzheimer's disease (AD) and controls

\begin{tabular}{|lccc|}
\hline Allele & Controls (\%) & AD patients (\%) & Value of $p$ \\
\hline G & $122(76.2)$ & $136(80.9)$ & 0.346 \\
\hline C & $38(23.8)$ & $32(19.1)$ & \\
\hline Total & $160(100)$ & $168(100)$ & \\
\hline
\end{tabular}

\section{Results}

No statistically significant difference between the observed and expected values in Hardy-Weinberg equilibrium was observed $(p>0.05)$.

The distribution of PTGS2 $-765 \mathrm{G} / \mathrm{C}$ showed no significant difference between patients with AD and controls. PTGS2 $-765 \mathrm{G} / \mathrm{C}$ genotype distributions in the cases and controls are presented in Table I. In addition, no significant difference in the $\mathrm{G}$ and $\mathrm{C}$ allele frequency between $\mathrm{AD}$ patients and controls was observed $(p>0.05)$ (Table II). The power of the study is $28 \%$ calculated by the methods of Cohen [13].

\section{Discussion}

This preliminary study in Sicilian patients with AD showed that PTGS2 $-765 \mathrm{G} / \mathrm{C}$ alleles and -765 $\mathrm{C} / \mathrm{C}$ genotype seem not to be associated with the risk of developing AD. These data agree with the data obtained by other authors [8]. The role of PTGS2 in neurodegenerative diseases is very controversial, and conflicting data exist in the literature [7, 8, 14]. For instance, although some studies have demonstrated that the increase in PTGS2 activity greatly contributes to the progression of $A D$ [7], other investigators have suggested an entirely opposite effect [8]. In this latter study, the $C$ allele of PTGS2 $-765 \mathrm{G} / \mathrm{C}$ promoter polymorphism was associated with decreased risk of $A D$, a finding which further supports the involvement of PTGS2 in AD etiology. Abdullah et al. reported that the C allele of COX-2 -765 promoter polymorphism is associated with decreased risk of $A D$ in their sample of 168 AD cases (recruited from the Memory Disorder Clinics in Tampa and in Miami, Florida) [7]. In fact, the rare C allele is associated with approximately $30 \%$ less expression of COX-2 compared to the more commonly occurring $G$ allele [15]. A study of Listi et al. suggests that the $G$ allele of COX-2 -765 could be a risk factor for $A D$ in a population from Northern Italy [16]. Fehèr et al. indicate that the COX-2 G/G genotype is associated with $A D$ and support the involvement of COX-2 in AD etiology [17]. In addition, in the study of Tang et al., no significant difference in the distributions of COX-2 -765G/C polymorphism was observed between $A D$ cases and controls [18].

Our data do not seem to associate this polymorphism with $A D$, at least in the Sicilian population, but in light of the limited power of the study (28\%) our conclusions should be evaluated with caution. In any case, further and broader studies are needed to confirm the role of PTGS2 $-765 \mathrm{G} / \mathrm{C}$ polymorphism in AD. We plan to extend our preliminary analysis to a larger cohort of Sicilian patients with $A D$ in the near future.

\section{References}

1. WHO, Dementia: a public health priority. World Health Organization 2012.

2. Querfurth HW, LaFerla FM. Alzheimer's disease. N Engl J Med 2010; 362: 329-44.

3. Dubois RN, Abramson SB, Crofford L, et al. Cyclooxygenase in biology and disease. FASEB J 1998; 12: 1063-73.

4. Qin Y, Tian YP. Protective effects of total glucosides of paeony and the underlying mechanisms in carbon tetrachloride-induced experimental liver injury. Arch Med Sci 2011; 7: 604-12.

5. Saunders AJ, Bertram L, Mullin K, et al. Results of a high-resolution genome screen of 437 Alzheimer's disease families. Hum Mol Genet 2003; 12: 23-32.

6. Hoozemans JJ, Rozemuller AJ, Janssen I, De Groot CJ, Veerhuis R, Eikelenboom P. Cyclooxygenase expression in microglia and neurons in Alzheimer's disease and control brain. Acta Neuropathol 2001; 101: 2-8.

7. Abdullah L, Ait-Ghezala G, Crawford F, et al. The cyclooxygenase $2-765 C$ promoter allele is a protective factor for Alzheimer's disease. Neurosci Lett 2005; 395: 240-3. 
8. Tang W, He M, Yang B, Wei K, Yin M, Zhang L. Association study of polymorphisms in the cyclooxygenase-2 gene and Alzheimer's disease risk in Chinese. Neurol Sci 2013; 34: 695-9.

9. Ahmadian A, Ehn M, Hober S. Pyrosequencing: history, biochemistry and future. Clin Chim Acta 2006; 363: 83-94.

10. Gharizadeh B, Herman ZS, Eason RG, Jejelowo O, Pourmand N. Large-scale pyrosequencing of synthetic DNA: a comparison with results from Sanger dideoxy sequencing. Electrophoresis 2006; 27: 3042-7.

11. McKhann GM, Knopman DS, Chertkow H, et al. The diagnosis of dementia due to Alzheimer's disease: recommendations from the National Institute on AgingAlzheimer's Association workgroups on diagnostic guidelines for Alzheimer's disease. Alzheimers Dement 2011; 7: 263-9.

12. Skarke C, Schuss P, Kirchhof A, et al. Pyrosequencing of polymorphisms in the COX-2 gene (PTGS2) with reported clinical relevance. Pharmacogenomics 2007; 8: 1643-60.

13. Cohen J. Statistical power analysis for the behavioral sciences (2nd ed.). Lawrence Erlbaum, New Jersey 1988.

14. Minghetti L, Pocchiari M. Cyclooxygenase-2, prostaglandin E2, and microglial activation in prion diseases. Int Rev Neurobiol 2007; 82: 265-75.

15. Levy-Lahad E, Wijsman EM, Nemens E, et al. A familial Alzheimer's disease locus on chromosome 1. Science 1995; 269: 970-3.

16. Listì F, Caruso C, Lio D, et al. Role of cyclooxygenase-2 and 5-lipoxygenase polymorphisms in Alzheimer's disease in a population from northern Italy: implication for pharmacogenomics. J Alzheimers Dis 2010; 19: 551-7.

17. Fehér A, Juhász A, Rimanóczy A, et al. Association study of interferon-gamma, cytosolic phospholipase A2, and cyclooxygenase-2 gene polymorphismsin Alzheimer disease. Am J Geriatr Psychiatry 2010; 18: 983-7.

18. Tang W, He M, Yang B, et al. Association study of polymorphisms in the cyclooxygenase- 2 gene and Alzheimer's disease risk in Chinese. Neurol Sci 2013; 34 695-9. 